\title{
Calcifying aponeurotic fibroma: a case report
}

\section{Fibroma aponeurótico ossificante: relato de caso}

\author{
1. Universidade Estadual de Campinas, Campinas, SP, Brazil. \\ 2. Instituto Vita, São Paulo, SP, Brazil. \\ 3. Hospital Sírio-Libanês, Brasília, DF, Brazil.
}

\begin{abstract}
Calcifying aponeurotic fibroma (CAF) is a rare lesion that can affect the feet and should be considered as a differential diagnosis of plantar tumors. The treatment is given by surgical resection, and the definitive diagnosis is confirmed by histopathological analysis. This case report shows a 17-year-old patient with CAF, the concept of the treatment performed, and emphasizes the importance of proper imaging planning to reduce risks and recurrence.
\end{abstract}

Level of Evidence V; Therapeutic Studies; Expert Opinion.

Keywords: Fibroma; Foot; Tumor; Surgery.

\section{RESUMO}

O fibroma aponeurótico calcificante (FAC) é uma lesão rara que pode acometer os pés, devendo ser considerado como diagnóstico diferencial dos tumores plantares. O tratamento é dado pela ressecção cirúrgica, sendo o diagnóstico definitivo comprovado pela análise histopatológica. O presente relato de caso mostra a apresentação e tratamento de um paciente de 17 anos com FAC e, ressalta a importância do planejamento adequado com base em imagens para diminuir riscos e postergar as recidivas.

Nível de Evidência V; Estudos Terapêuticos; Opinião do Especialista.

Palavras-chave: Fibroma; Pé; Tumor; Cirurgia.

How to cite this article: Oliveira LB, Maranho D, Garofo KV, Mattos e Dinato MC. Calcifying aponeurotic fibroma: a case report. Sci J Foot Ankle. 2019;13(4):264-8.

\section{INTRODUCTION}

Calcifying aponeurotic fibroma (CAF) is a rare benign tumor of fibroblastic origin with locally aggressive behavior $^{(1)}$ that typically develops in the fascia and tendons of the palms or soles of children and adolescents. Although it has been described in several age groups, the peak incidence occurs between 8 and 14 years of age and it is twice as frequent in males as in females ${ }^{(2-5)}$. The main sites of involvement are the hands $(77 \%$ on palms and fingers) and the feet $(13 \%)^{(6)}$. The typical presentation of the tumor is as a painless, locally aggressive, subcutaneous, poorly defined, firm mass of slow growth that is not adherent to the skin, but to the adjacent subcutaneous tissue ${ }^{(6)}$. Malignant transformation is rare, though change into fibrosarcoma has already been described ${ }^{(2,7)}$, as well as metastases to bone and lungs. The lesion is not easily identified on radiographs. The most recommended supplementary assessment for diagnosis and preopera-

Study performed at the Instituto Vita, São Paulo, SP, Brazil.

Correspondence: Larissa Barbosa Oliveira. Rua: Mato Grosso 306, $1^{\circ}$ andar, Higienópolis, São Paulo, SP, Brazil. CEP: 01239-040

Conflicts of interest: none. Source of funding: none.

Date received: November 19, 2019. Date accepted: December 18, 2019. Online: December 23, 2019. 
tive planning is magnetic resonance imaging (MRI), as it enables evaluating the extent of lesion margins and the complexity of calcifications ${ }^{(1,7,8)}$.

Differential diagnoses of CAF include synovial sarcoma, undifferentiated pleomorphic sarcoma, mainly in the hands and wrists ${ }^{(9)}$, epithelioid sarcoma, clear cell sarcoma, giant cell tumor of tendon sheath, soft tissue chondroma, palmar or plantar fibromatosis, Morton's neuroma, and peripheral nerve sheath tumor (Schwannoma). The recommended treatment is complete surgical excision including the oncological margins ${ }^{(6,7)}$, followed by a histological analysis and a immunohistochemical analysis ${ }^{(8)}$. Due to the locally invasive pattern, after surgical excision, CAF has a high rate of recurrence ${ }^{(1,3,5)}$.

The purpose of this study is to present a case report of CAF and the concept of the treatment performed, as well to present a literature review on CAF to highlight the possibility of this specific diagnosis considering the differential diagnoses of tumors that affect the foot.

\section{CASE REPORT}

This study was approved by the Ethics Committee, being registered on Plataforma Brasil under CAAE number 23237719.7.0000.5404, and follows Brazilian and international guidelines on ethics in research involving human participants. An informed consent form was signed.

The patient was a 17-year-old male adolescent complaining of sporadic pain and tumor in the plantar region of the left forefoot for seven years. There was no history of trauma and the condition was slowly progressive, with pain worsening with physical activity. Upon examination, a tumor of moderately hard consistency was found in the plantar region, below the first metatarsal and appose to the lateral sesamoid. Interfalangeal hallux valgus was present, with no skin changes, neurovascular changes, or instability of the first ray. The initial clinical suspicion was a relatively deep and adherent tumor or fixed sesamoid dislocation. Radiographs and MRI of the left forefoot were requested.

On the initial radiograph (Figure 1), it was possible to observe an enlargement of the space between the first and second metatarsals of the left foot, normal positioning of the sesamoids, and interphalangeal hallux valgus. It was further possible to notice small proximal calcifications between the first and second metatarsals.

On MRI (Figure 2), an elongated, lobulated tumor lesion was identified adjacent to the plantar contour of the lateral sesamoid of the hallux, with multiple intralesional calcified foci. The tumor extended proximally to the medial belly of

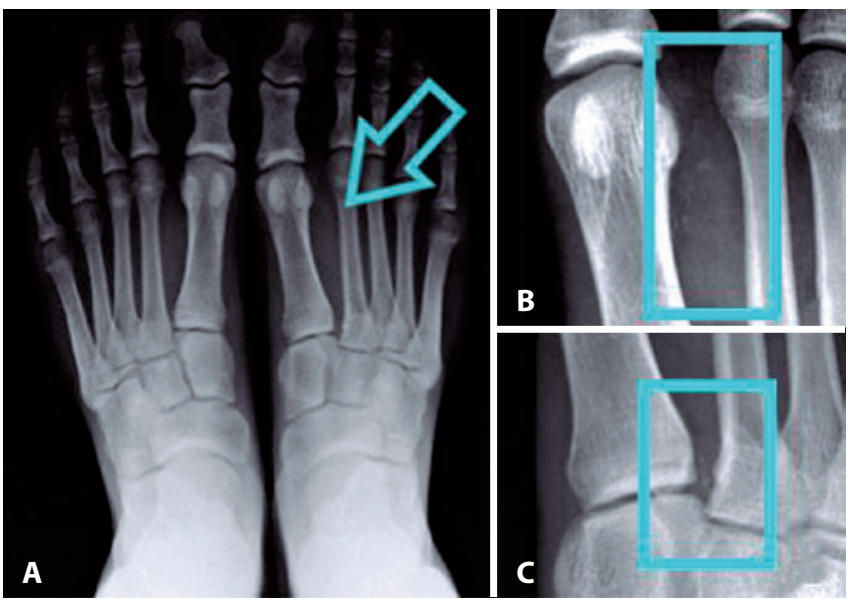

Figure 1. (A) Weight-bearing AP radiograph with a slight varus alignment of the left first metatarsal, asymmetrical, with increased intermetatarsal space (arrow). (B) In detail, calcifications between the head of the first and second metatarsals. (C) In detail, calcifications between the bases of the first and second metatarsals next to the Lisfranc joint.

Source: Author's personal archive.

the flexor hallucis brevis and underlying plantar fat, measuring $4.0 \mathrm{~cm}$ long $\times 1.9 \mathrm{~cm}$ deep $\times 1.8 \mathrm{~cm}$ wide. The signal was predominantly low on $\mathrm{T} 1$ and $\mathrm{T} 2$, with evidence of enhancement after the administration of paramagnetic contrast, especially in late sequences. There was also another small lesion with the same characteristics next to the plantar and lateral contour of the first tarsometatarsal joint, next to the insertion of the peroneus longus tendon. Potentially, the tumoral lesion showed no signs of aggressiveness, which is compatible with the time of clinical evolution, and a possible vascular origin with calcified/fibrous component was considered as a diagnostic hypothesis.

The treatment performed was the complete surgical excision of the plantar mass in the forefoot, adjacent to the lateral sesamoid, including resection of the sesamoid. During resection, the tumor extension to the flexor hallucis longus was confirmed. The tumor affected the tendon and the fibroadipose and muscle tissues, extending to the periosteum of the first metatarsal without, however, infiltrating it, thus the margin of this bone was not to resected. The anatomopathological analysis identified a fasciculated, sclerosing, infiltrative, moderately cellular spindle cell proliferation, with the formation of calcified nodules of chondroid matrix, calcified metaplasia, and cartilaginous and bone metaplasia, defining the diagnosis as CAF.

At the initial follow-up, the patient remained without symptoms, pain, or new tumors, resuming the practice of 

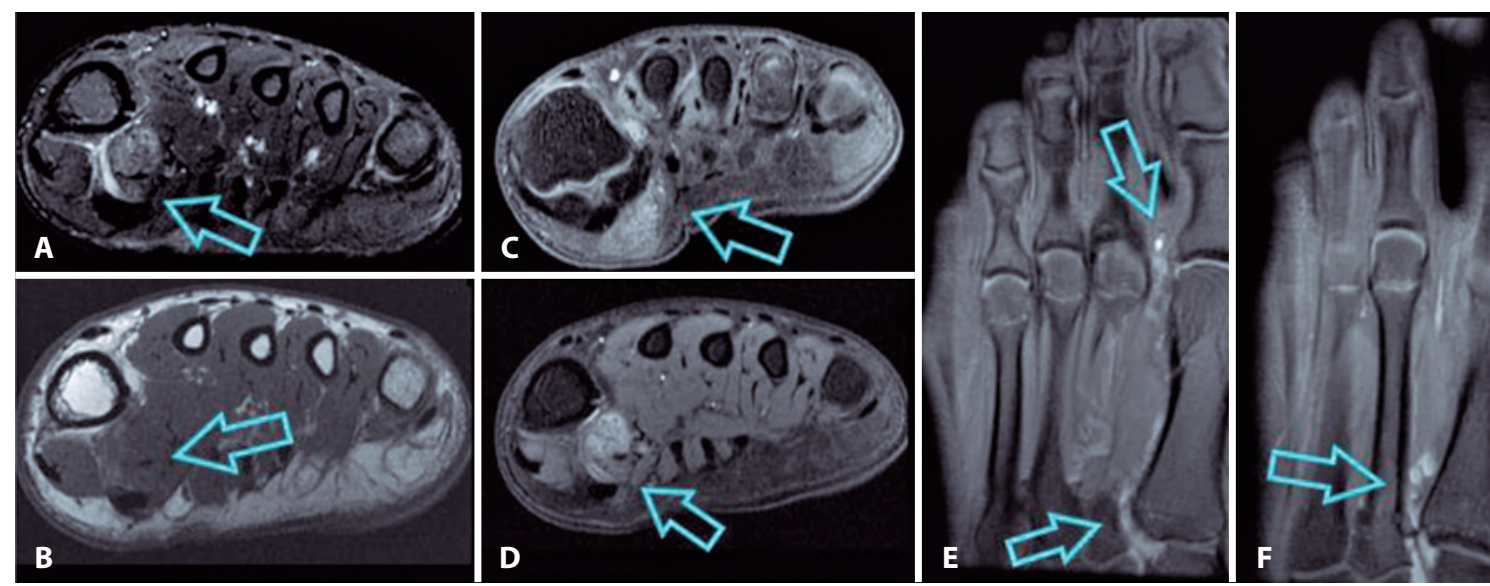

Figure 2. Axial MRI images with low and moderate intensity signal on T2 (A) and low intensity signal on T1 (B) showing a plantar tumor lesion lateral to the first ray, with multiple suggestive intralesional calcified foci (arrow). T2 axial post-contrast image (C), with the plantar tumor lateral to the lateral sesamoid enhanced after contrast (arrow) and with proximal extension through the medial belly of the flexor hallucis brevis (D; arrow). In post-contrast T2 coronal sections, a lesion is observed in the first intermetatarsal space distally (E; arrow) and proximally ( $F$; arrow), next to the Lisfranc joint.

Source: Author's personal archive.

physical activities after wound healing. On control radiograph four months after surgery, an increase in the proximal space between the first and second metatarsals persisted. On control MRI (Figure 3) six months after surgery, there was a change in the plantar and lateral signal to the first metatarsal at the site of the surgical scar, but without clear evidence of recurrence.

One year after surgical resection, the patient remained asymptomatic, however, on the control MRI (Figure 4), tumor recurrence was observed with characteristics similar to the first examination. The lesion was measuring $1.1 \times 0.9$ $x 0.6 \mathrm{~cm}$. Besides, changes to the tissue that infiltrated the first intermetatarsal space were more evident and involved the Lisfranc ligament, with larger components in the plantar and lateral portions.

As the patient remained asymptomatic, with no changes in daily activities, without restriction of movements or other complaints, and without palpable masses, it was decided to perform control MRIs and maintain clinical follow-up, which to date totals 19 months.

\section{DISCUSSION}

Calcifying aponeurotic fibroma is a rare benign tumor that affects mainly the hands and feet of children and adolescents. It has already been described in other body parts, such as the mandible, neck, scalp, forearm, thigh, knees, abdomen, and lumbosacral region ${ }^{(7,10)}$. Keasby first descri- bed it in 1953 as a juvenile aponeurotic fibroma, also called juvenile fibromatosis $\mathrm{s}^{(1,7,10)}$. Patients present poorly defined, hard, small masses of soft tissues of slow growth ${ }^{(5,10)}$. The epidemiological presentation of our case is quite typical: a 17-year-old male adolescent with plantar tumor of slowly progressive growth since he was ten years old.

On radiographs, it is possible to find multiple or speckled calcifications and bone erosions( ${ }^{(4)}$, although cortical erosion is rarely seen ${ }^{(9)}$. At the initial radiographic examination, there were thin plantar calcifications in the first intermetatarsal space up to the Lisfranc joint and an enlargement between the first and second metatarsals. However, such radiograph is not enough for a definitive diagnosis. MRI and computed tomography are the preferred examinations to diagnose and define the lesion. Tomography may reveal an unspecific soft tissue mass with dotted calcification and may show the infiltrative growth pattern of the lesion into surrounding tissues ${ }^{(10)}$. On MRl, the findings include poorly defined soft tissue mass with speckled calcifications with a low or intermediate intensity signal on $\mathrm{T} 1$ and an image of intermediate to high intensity on T2. On T2, areas of heterogeneity are also observed, with few areas of low or intermediate intensity ${ }^{(3,4)}$, being affected by the degree of calcification, reduced cellularity, and quantity of fibrous components ${ }^{(4)}$. As demonstrated, the heterogeneous image shows an increased signal after injection of gadolinium contrast ${ }^{(3)}$, which may be diffuse or with peripheral enhancement ${ }^{(9)}$. 

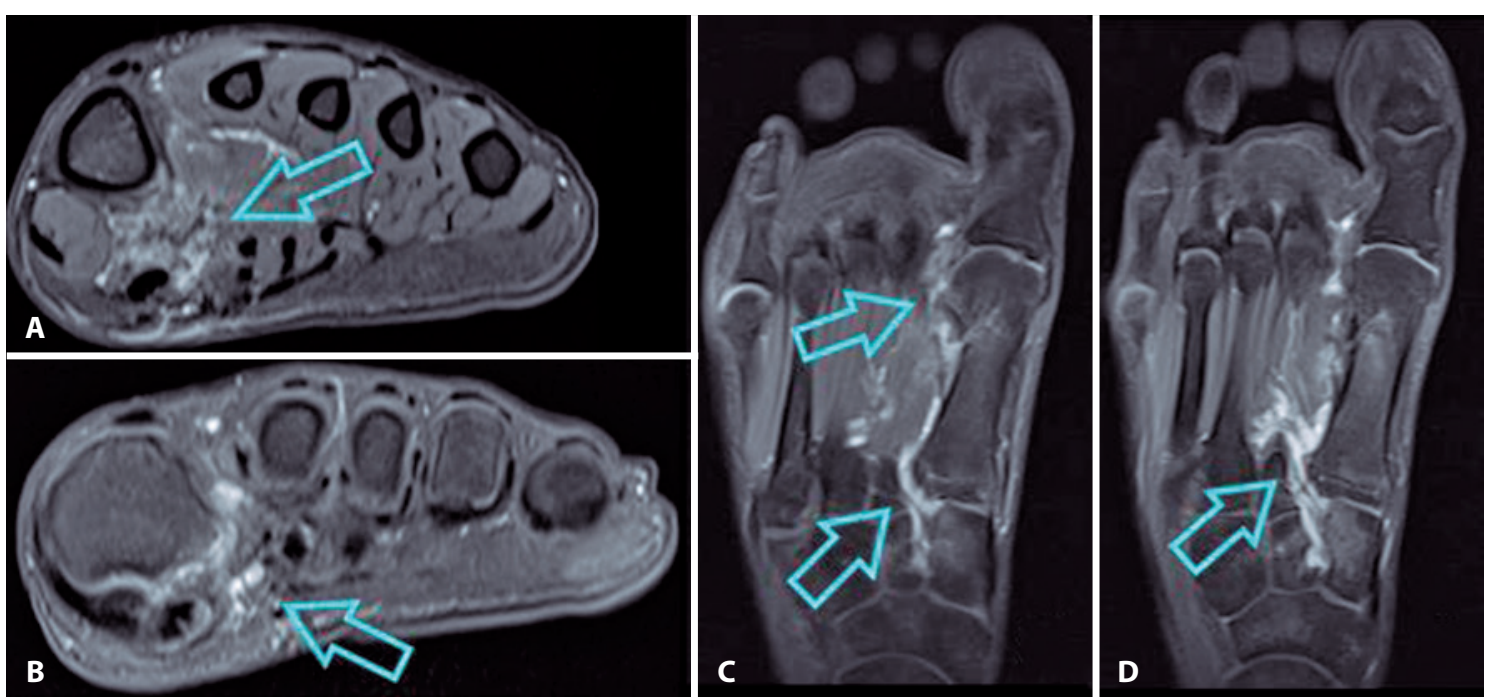

Figure 3. MRI images with fat suppression six months after surgery, with axial T2-weighted cuts ( $A$ and $B)$ and coronal cuts $(C$ and $D)$ that show sign changes at the surgical scar site (arrows), but without clear evidence of recurrence. Source: Author's personal archive.
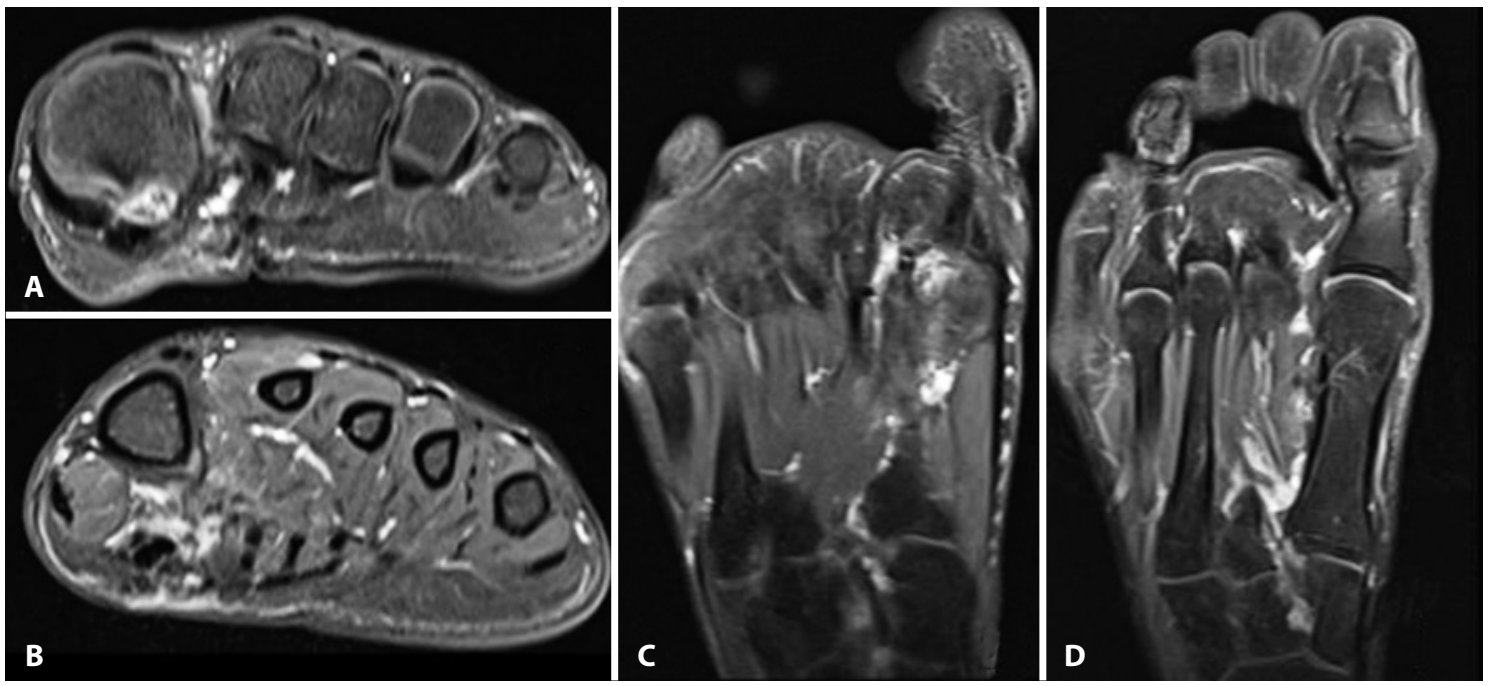

Figure 4. MRI images with fat suppression one year after surgery, with axial T2 cuts ( $A$ and $B$ ) and coronal cuts (C and D) that show changes in the plantar and lateral signs on the first metatarsal, with enhancement peripheral to the evident tumor lesion, characterizing a recurrence of calcifying aponeurotic fibroma.

Source: Author's personal archive.

In the present case, as there was no evidence of malignancy in the images and considering the history of slow and progressive growth, a surgical excision of the tumor was performed. The lesion extended to the medial belly of the flexor hallucis brevis, with multiple foci of calcifications inside of it. Although it is located in the subcutaneous layer in about $80 \%$ of cases, CAF can present inter or intramuscular involvement ${ }^{(4)}$. The exact limits were not evident during our surgical excision, and as the tumor involved the lateral sesamoid, it was decided to resect it en bloc with the affected soft parts. However, during surgery, it was not identified whether the lesion extended proximally to the first tarsometatarsal joint or if there was an isolated focus other than the proximal lesion. No frozen-section biopsy of the margins was performed during surgery due to the benign nature of the lesion.

The definitive diagnosis is based on histological findings, immunohistochemical tests, and ultrastructural 
studies. On histopathological analysis, CAF has a biphasic morphology, with moderate and infiltrative cellularity, a component similar to fibromatosis, and calcification nodules accompanied by rounded epithelioid cells, with infrequent mitotic figures. The present case presented similar findings, with moderately cellular, infiltrative spindle cell proliferation, formation of nodules of chondroid matrix, and cartilaginous and bone metaplasia.

The infiltrative nature of CAF is manifested by high rates of recurrence, higher than $50 \%$, which can take years after the initial excision ${ }^{(1,2,5)}$. The risk of local recurrence appears to be higher in younger children, and, in general, recurrence is not destructive ${ }^{(1,5)}$. In this case report, a tumor was observed about a year after surgery in a patient in late adolescence. It was not possible to conclude if there was a tumor remaining due to incomplete surgical resection or if it was an earlier recurrence of the CAF comparing with what is described in the literature.

\section{CONCLUSION}

In conclusion, CAF is a rare lesion that can affect the feet and should be considered as a differential diagnosis of plantar tumors. It is treated by surgical resection and its definitive diagnosis is confirmed by histopathological analysis, there being high rates of recurrence. The present case highlights the importance of a proper planning with images to reduce risks and postpone recurrences.

Authors' contributions: Each author contributed individually and significantly to the development of this article: LBO *(https://orcid.org/0000-0002-86066187) conceived and planned the activities that led to the study, wrote the article, interpreted the results of the study, participated in the review process, approved the final version; DM *(https://orcid.org/0000-0002-3893-0292) participated in the review process, approved the final version; KVG *(https:// orcid.org/0000-0001-5025-0823) interpreted the results of the study, participated in the review process, approved the final version; MCMD *(https://orcid. org/0000-0001-6572-1771) conceived and planned the activities that led to the study, wrote the article, interpreted the results of the study, participated in the review process, approved the final version. *ORCID (Open Researcher and Contributor ID).

\section{REFERENCES}

1. Keasbey LE. Juvenile aponeurotic fibroma (calcifying fibroma); a distinctive tumor arising in the palms and soles of young children. Cancer. 1953;6(2):338-46.

2. Corominas L, Sanpera I, Sanpera-Iglesias J, Ramos-Ansesio RF. Calcifying aponeurotic fibroma in children: Our experience and a literature review. J Pediatr Orthop Part B. 2017;26(6):560-4.

3. Nishio J, Inamitsu H, Iwasaki H, Hayashi H, Naito M. Calcifying aponeurotic fibroma of the finger in an elderly patient: CT and MRI findings with pathologic correlation. Exp Ther Med. 2014;8(3):841-3.

4. Shim SW, Kang BS, Lee CC, Suh JH, Shim HS. MRI features of calcifying aponeurotic fibroma in the upper arm: a case report and review of the literature. Skeletal Radiol. 2016;45(8):1139-43.

5. Fletcher CDM, Bridge JA, Hogendoorn P, Mertens F, editors. IARC
WHO classification of tumours of soft tissue and bone. $4^{\text {th }}$ ed. Geneva: WHO Press; 2013.

6. Khullar G, De D, Tripathy S, Prakash M, Saikia U, Handa S. Painful calcifying aponeurotic fibroma. Indian J Dermatol Venereol Leprol. 2016;82(4):449-52.

7. Sheikh RN, Karlic K. Calcifying aponeurotic fibroma of the hallux. J Am Podiatr Med Assoc. 2018;108(1):68-73.

8. Cho YH, Ahn K-S, Kang CH, Kim CH. Calcifying aponeurotic fibroma of the dorsum of the foot in a four-year-old boy: a case report with radiographic and magnetic resonance findings. Iran J Radiol. 2015;12(2):10-2.

9. Kim OH, Kim YM. Calcifying aponeurotic fibroma: Case report with radiographic and MR features. Korean J Radiol. 2014;15(1):134-9.

10. Schonauer F, Avvedimento S, Molea G. Calcifying aponeurotic fibroma of the distal phalanx. Br J Plast Surg. 2013;66(2):e47-9. 